\title{
6 Helping new D\&T teachers to analyse and develop knowledge and understanding in design and technology (product design)
}

Matt McLain

\section{Introduction}

In other chapters we have seen, and will see, that the current professional standards for teachers in England require that beginning teachers demonstrate a high level of subject knowledge and pedagogy (DfE 2011, p. 11), including keeping up to date with developments - particularly relevant to the rapid changing nature of technology that affects the design and technology (D\&T) curriculum. Similar statements are part of the professional knowledge and understanding standards for the General Teaching Councils for Scotland (GTCS) and Northern Ireland (GTCNI).

It is a commonly held view that teachers' subject knowledge is an essential component of effective teaching (DfE 2010, 2011; Shulman 1986), alongside effective pedagogical/didactic skills, and contextual knowledge of learners, schools and policy. In a recent study of D\&T teachers' views about demonstration as a signature pedagogy, competence with regard to subject knowledge was ranked higher than pedagogical approaches that consolidated learning and facilitated independence (McLain 2017).

However, research indicates that subject knowledge does not appear to be the most important factor, though it may influence 'teaching effectiveness up to some level of basic competence but less so thereafter' (Hattie 2009, pp. 113-114). The teacher's empathy (to understanding learning and learners) and verbal ability (articulation of concepts and processes), combined with subject knowledge, together appear to be essential characteristics of effective teaching: 'greater than the 
sum of the parts and if one is missing the effectiveness is reduced by more than a third' (p. 115).

The ability to deconstruct, reconstruct and communicate knowledge, engaging learners at their current level of attainment, is an essential skill for teaching, making subject competence a threshold standard, rather than a defining feature.

This chapter focuses on the tricky topic of teacher knowledge in D\&T, how to help beginning teachers analyse and develop it, during initial teacher education (ITE) and early career development (Task 6.1).

\section{Objectives}

At the end of this chapter, you should be able to:

- Reflect on and recognise the complex nature of teachers' knowledge.

- Identify the key elements of D\&T knowledge.

- Identify, analyse and document your areas of strength and for development.

- Plan early career subject knowledge development.

\section{What is knowledge?}

\section{Task 6.1 Knowing knowledge}

Thought experiment - What does it mean to know something? Identify an aspect of D\&T knowledge that you know that a beginning teacher needs to develop, such as user-centred design. What knowledge you need to (a) explain what it means, (b) demonstrate how to do it and (c) enable learners to do it, capably and/or autonomously? How do factors such as the age of the learner affect the required knowledge? How do you know when you have sufficient knowledge? The nature of knowledge is a complex and much debated area with its own field of study, epistemology, dating back to philosophers in ancient Greece (Scharff and Dusek 2003). Plato 
defined knowledge as 'justified true belief', a view much debated in the intervening years (Gettier 1963). Indeed, some of the problems with knowledge in D\&T and modern assumptions about the relationship between theory and practice may stem from translations of the Greek words epistêmê (commonly translated as knowledge) and technê (translated as craft or art). The word technology stems from the Greek technê and epistemology from episteme further reinforcing an apparent division informing the knowledge verse skill debate ( $c f$ Scharff and Dusek 2003).

Ryle (1949) proposed a more helpful approach to knowledge, for our purposes: knowing that (conceptual) and knowing how (procedural), an idea more recently applied to technology education by McCormick (1997). This view of knowledge removes the division between mind (thinking) and body (acting), which has fuelled the debate around whether D\&T is academic, practical, creative and/or vocational, since its introduction to the curriculum in the later part of the twentieth century (Kimbell, Stables and Green 1996). McCormick (1997, p. 143) describes conceptual knowledge as being actively concerned with relationships between "items" of knowledge' as opposed to a passive 'collection of unrelated facts'; and procedural knowledge relates to the application of knowledge, such as process, problem solving and strategic thinking. The mentor can assist the beginning D\&T teacher to gain an understanding that, in addition to cultivating subject knowledge, they must also develop 'teacher knowledge' and 'knowledge for teaching'. Teacher knowledge encapsulates the aforementioned ability to successfully articulate knowledge taking account of prior and age-related learning. Knowledge for teaching focuses on the knowledge of internal and external curricular frameworks, including formal and terminal examinations, and how to develop personal capability, pedagogy and didactics. In the following sections, we will explore the nature of knowledge for the teacher and in D\&T. 


\section{What is teacher knowledge?}

Shulman (1986) proposed three categories of professional teacher knowledge: subject content knowledge, pedagogical content knowledge and curricular knowledge. When exploring how teachers view practice Shulman described teacher knowledge in terms of principles, maxims and norms. Principles being areas of knowledge supported by the wider body of research, maxims as the everyday practice and experience of teachers (that might be thought of as generally conscious or tacit accepted practices) and norms the values and philosophical perspectives of the individual and institutions, which influence and inform practice.

The mentor can use Shulman's principles, maxims and norms as a framework to aid reflection and challenge the beginning teacher's assumptions, to develop self-awareness and depth of knowledge. For example, research (principle) might indicate that collaborative design activities are effective in developing pupils' ideation (idea generation and development) skills. However, the beginning teacher's experience might be limited to pupils working on design ideas individually and build a range of assumptions, reinforced by what they observe in other classrooms (maxim). Furthermore, when introducing new practices into teaching they may appear to be unsuccessful, which may be because there is not yet a culture in the classroom that promotes this way of learning, or there is a lack of shared confidence (norm).

Beginning teachers have a limited experience to drawn on as well as limited access to what Shulman describes as 'cases' - examples of practice. Similarly, an experienced teacher can be biased by the availability of the 'cases' they have observed in their lessons, or those of colleagues. Therefore, mentor and beginning teachers' engagement with the wider D\&T community of practice through research, professional updates and dialogue with teachers in other schools is essential to developing and maintaining an open mind to new ideas and a broader 
perspective on the effectiveness of differing pedagogical approaches to subject teaching. This in turn, facilities strategic knowledge expressed through effective lesson and curriculum design (Task 6.2).

\section{Task 6.2 Perspectives}

An effective starter to a mentoring conversation around teacher knowledge might begin with 'In 5 years' time, when you are a head of department...' Discuss the opportunities and challenges of curriculum design and teacher knowledge in D\&T. What are the differences in perspective between the mentor and the beginning teacher?

Banks, Leach and Moon (2005), building on the work of Shulman, introduced graphic model (Figure 6.1) to support the development of reflection in D\&T ITE, where school knowledge expands curricular knowledge, focusing on the didactic transformation of knowledge (including curriculum and classroom management) and context (including cultural, historical and ideological factors).

\section{<COMP: Place Figure 6.1 Here>}

Mentors can use these categories with beginning teachers to discuss emerging and developing knowledge, recognising that subject knowledge is not an 'entity' in its own right, unaffected by context. For example, in a D\&T food lesson, the teacher might be introducing knife skills to pupils. The beginning teacher needs not only to be knowledgeable about correct and safe technique (bridge and claw methods) and tools (the correct knife and cutting board), but also mindful of the constraints of what pupils (a) know already, (b) can observe during a demonstration and (c) can access in a large classroom (pedagogical knowledge). They must also be aware of the place the demonstration has in the wider curriculum and cultural norms in the 
school (school knowledge). In this manner, the mentor can use these three categories as 'lenses' through which to view knowledge and experience in the classroom. Vygotsky (1978) introduced the idea of the More Knowledgeable Other (MKO) where the teacher has a knowledge and understanding of a subject that the learner does not yet possess, and the role of the MKO is to make learning explicit in a meaningful context. The role of a mentor is to support the beginning D\&T teacher, when developing an aspect of their subject knowledge, to gain an 'understanding of a process, including sequence, related knowledge and next steps' (McLain 2017, p. 2). This is more than being able to repeat a procedure competently, it is deliberate practice (Ericsson and Pool 2016), where a mentor provides feedback and the beginning teacher reflects with the aim of developing expertise. This feedback is an important means of 'holding a mirror to' a beginning teacher's practice. A skilful mentor will recognise this, framing feedback that reflects observations to prompt self-evaluation, rather than making an immediate judgement - for example 'I notice that learners..., how could you...?' rather than 'You need to develop... for the next lesson' (Task 6.3).

\section{Task 6.3 Framing feedback}

Have a mentoring conversation with a beginning teacher about their developing subject knowledge, without giving direct instructions. Focus on observations ('I noticed that...' and use questions to (a) draw out the impact that their subject knowledge had on learning and progress in the lesson and (b) identify actions for the next lesson.

Vygotsky's social constructivism focuses on how human beings learn through social interaction with peers and experts. The learner is supported by a MKO to realise personal potential, described as the 'within reach and yet to be grasped' Zone of Proximal Development (ZPD). The $\mathrm{ZPD}$ 'is the distance between the actual developmental level... and the level of potential 
development... under adult guidance or in collaboration with more capable peer' (p. 86).

Therefore, the role of a teacher is to facilitate learning through approaches that are teachercentric (e.g. modelling, explaining and questioning) and learner-centric (e.g. discovery learning, group work and designing). This is where the idea of scaffolding learning comes from, and what you must help the beginning teacher to realise is that at some point (to continue the metaphor), the scaffolding needs to come down and the structure (learning) must stand on its own (Task $6.4)$.

\section{Task 6.4 Developing independence}

Identify a procedure that learners use repeatedly throughout their schooling in D\&T, such as using a drilling or a sewing machine. Plan a demonstration for a group of 11 year olds using the procedure for the first time. What are the key steps in the process? What are the health and safety considerations? Now plan how you would teach the same skill to the same group in three years' time. How would you adapt your approach? What are the risks of not using a scaffolded approach? (i.e. always demonstrating in the same way.)

In order to take on the role of the MKO, the beginning D\&T teacher must not only model and explain concepts or procedures, they must also understand them in order to identify and address misconceptions or incorrect practice. For example, when teaching pupils to solder an electronic circuit board, the beginning D\&T teacher should understand why it is important to heat both the pad on the board and the component leg in order to make a complete joint between both surfaces. This includes (a) what it looks like when it is effective and it is not and (b) how to diagnose errors (including those that cannot be observed visually). By working with a beginning D\&T teacher to develop subject knowledge, the mentor is able to discuss how deeper subject 
knowledge helps them to assess pupils' understanding. In this way, the mentor aids the beginning teacher's deliberate practice.

Similarly, the beginning D\&T teacher's knowledge of design processes and techniques will help them plan activities, for example, to avoid fixation on one or a limited range of ideas when pupils are designing (DfE, 2015a; McLellan and Nicholl, 2011).

Therefore good subject knowledge helps the beginning D\&T teacher, not only to plan effective learning, by identifying the correct steps and sequences, but also to formatively and diagnostically assess pupils' progress, identify and address barriers to learning and promote progress.

\section{What is D\&T knowledge?}

D\&T knowledge is 'multi-dimensional' (McCormick 1997, p. 144), requiring interaction between thinking and acting. Kimbell et al. (1991) discuss the essential interaction between mind and hand, articulated in Figure 6.2, reflecting the essential role that designing and making play in D\&T activity, undergirded by critiquing skills. The notion of 'task-action-capability' has been a feature of D\&T, involving active and purposeful use of knowledge, often through extended design and make projects (Kimbell and Perry 2001). Knowledge in D\&T is complex and extends beyond the boundaries of school subjects, as recognised in national and school curricula (Black and Harrison 1985).

<COMP: Place Figure 6.2 Here>

In addition to knowledge about technological principles, concepts and processes (including the manipulation of materials and control of processes), designing and making is an essential component of D\&T learning. This can be expressed as design and make (or design, make and evaluate) activities, with the associated benefits of the aforementioned mind and hand interaction 
through ideation and modelling, as well as the inherent limitations of the resources, facilities and knowledge available. Alternatively, focused tasks involving mainly making with limited or no design input (Banks and Owen-Jackson 2007) have also been popular pedagogical approaches in D\&T, providing opportunity to learn and replicate craft skills and technical processes, with limited opportunity for creativity (Barlex and Trebell 2008). However, there is a risk that in teaching D\&T solely through activities that involve the making of products/prototypes that these become merely making activities masquerading as design and make, with a thin veneer of aesthetic design. Similarly, even genuine design and make activities have their limitations, as outlined above. Other approaches that encompass the wider aspects of creativity and critique include mainly designing activities, or designing without making (Barlex 2006; Barlex and Trebell 2008) and exploring technology and society (Barlex 2003). When approaching subject knowledge, it is important for the mentor and beginning teacher to be cognisant of not just the procedural knowledge (knowing how) of a technological procedure, but also of the context of how it is applied and effective pedagogical approaches. In order to do this effectively, the mentor and beginning teacher must have an understanding of the signature pedagogies in D\&T, along with inherent benefits and limitations. For example, the demonstration as a signature pedagogy in D\&T (McLain, 2017) is a direct teaching method well suited to mainly making activities, yet can have a limiting effect on creativity in mainly designing activities (McLellan and Nicholl, 2011; Task 6.5).

\section{Task 6.5 Pedagogical approaches}

Read and discuss the papers by McLain (2017) and McLellan and Nicholl (2011), undertaking a SWOT (strengths, weaknesses, opportunities and threats) analysis in relation to planning lessons for the following week. Discuss the benefits and limitations of 'restrictive' (e.g. direct teaching) 
and 'expansive' (e.g. discovery learning) pedagogical approaches in D\&T. What ideas will inform lesson planning for the next week?

\section{Challenges for D\&T knowledge}

Recognising the complexity of D\&T knowledge, there are four key challenges that may be helpful to articulate:

The first is that technology is a complex word, aside from D\&T as a curriculum entity. Mitcham (1994), reviewing various strands of the philosophy of technology, identifies four modes of the manifestation of technology: technology as object (products including clothing, utilities, tools and systems); technology as knowledge (skills, rules and theories); technology as activity (including designing and making); and technology as volition (including human motivation and intentionality). Viewing D\&T through one of these 'modes' to the exclusion of others may limit the experience of D\&T in the classroom.

The original intentions for D\&T in the National Curriculum in England looked beyond school D\&T “...not only to solve practical problems, to invent, optimise and realise solutions, but also so that we can acquire a sense of its enormous transformatory power" (DES/WO 1988, p. 6).

Second, it is important to acknowledge that D\&T is perceived to have a less clearly defined knowledge base than subject such as mathematics or science (DfE 2011). Bernstein (1990) explored the nature of school subjects and knowledge boundaries, developing a framework classifying subjects as having strong or weak boundaries, relating to bodies of knowledge (Bell, Morrison-Love, Wooff and McLain 2017). However, one of the great strengths of D\&T, and 
other subjects with so-called weaker boundaries, is the active and applied nature that draws on knowledge from other disciplines, and has a complex and changing nature, as both society and technology evolve.

Third, D\&T emerged in the late twentieth century from craft education, which defined 'material areas'. These material areas have historically defined the subject emerging out of the technical crafts (de Vries 2012), which had origins in the notion of gendered technology (Bell, Hughes, and Owen-Jackson 2013). Very simply, these origins can be presented as domestic science (including cooking and needlework) for girls and woodwork and/or metalwork for boys (systems and control emerged out of science). One of the aims of the National Curriculum for D\&T was to ‘provide equal opportunities for boys and girls' (DES/WO 1989, p. 96). These material areas became defined in England as discrete entities with their own external examinations, such as food, graphic products, resistant materials, systems and control, and textiles. Thus leading to the misconception that these material areas were the 'subject', and teachers developing identities were bound in historical craft divisions. Paetcher (1995) described this tendency to focus on material/craft knowledge as a sub-cultural retreat. McLain (2012) describes how school and departmental culture can affect an individual teacher's vision and values, maintaining the status quo when unchallenged. Despite this intention for D\&T to be one subject, the division of the subject by material area remained until 2017 in England, when the variety of General Certificate of Secondary Education (GCSE) ${ }^{1}$ titles were subsumed under one, 'Design and Technology' (DfE, 2015a) apart from food, with a separate 'Food Preparation and Nutrition' qualification (DfE, 2015b).

\footnotetext{
${ }^{1}$ The national external and terminal assessment for 16 year olds in England, Wales and Northern Ireland.
} 
Fourth, D\&T education is a relatively young and largely undertheorised subject. McLain, Bell, Wooff and Morrison-Love (2018) discuss D\&T as a cultural imperative, promoting children's understanding of designing and making, within a wider social and technological context. In other words, D\&T must be more than training the next generation of engineers, technologists and designers. Limiting the scope of the subject to practical, vocational, technical or other equality valid purposes, potentially distracts and distorts teachers' view of the subject and its importance. An effective mentor would do well to look beyond the practical and potentially mundane concerns (de Vries, 2005) of teaching to the curriculum, to open the beginning D\&T teacher's eyes to the potential of the subject to promote dispositions and alternative ways of interacting with the world. In exploring the nature of D\&T pedagogy, Morrison-Love (2017) discusses transformation as a key feature of the subject, akin to the proof in mathematics and interpretation in science. The very nature of D\&T is to provide children with a variety of physical and conceptual tools to view and change (or transform) the world around them to meet the needs and wants of individuals and society. In other words, D\&T knowledge is knowledge for active transformation (Task 6.6).

\section{Task 6.6 Cross curricular knowledge}

Identify an aspect of D\&T that draws on another discipline's body of knowledge, such as properties of materials in science or colour theory in art and design. List the similarities and differences between how this knowledge is used in the respective classrooms. What is unique about D\&T, with respect to the identified knowledge? What would be the impact on the D\&T curriculum if all 'shared' knowledge were omitted?

\section{D\&T knowledge in the curriculum}


As outlined above, D\&T knowledge is difficult to define, as it draws on many other subjects in the school curriculum, including mathematics, science, art and design, computing and the humanities as identified in the GCSE Subject Content taught from September 2017 in England (DfE 2015a). This document captured the views of stakeholders and outlines the subject content in three and a half pages, compared to one page in the previous version (QCA/WA/CEA 2007) as well as the current national curriculum programme of study (DfE 2013). This reflects attempts to address the perceived "weaker epistemological roots" for D\&T, information and communication technology and citizenship (DfE, 2011, p. 24) and other contemporary threats to the subject. However, the defused nature of D\&T subject knowledge can be viewed as a positive, considering the origins and intention of the subject.

Taking England as a case study in the United Kingdom, the current National Curriculum programme of study for D\&T (DfE 2013) breaks the subject down into four areas for the age range 5-14 as: design; make; evaluate; and technical knowledge; with an additional category of cooking and nutrition. The specific content relating only to the teaching of food reflects the direction of policy for food education at the time, which also led to a separate GCSE Food Preparation and Nutrition (DfE 2015b) - removing food as a D\&T material after the age of 14. The cooking and nutrition section expands on the technical knowledge section, which refers to structures and control systems embedded across the material areas.

Building on the National Curriculum, the GCSE D\&T subject content identified two categories of knowledge:

- technical principles (knowing that, or conceptual knowledge), including knowledge of: technologies and their impact; materials and energy; systems and control; 
- designing and making principles (knowing how, or procedural knowledge), including knowledge of: contextual factors, opportunities and limitations; ideation and realisation strategies;

However, curricula vary between countries and change over time, being influenced by a range of internal and external factors, such as governments' need to address issues with the health of a nation or the needs of industry, not to mention ideological leanings. Therefore, the intelligent and reflective mentor should help the beginning D\&T teacher to develop the ability to evaluate and renew subject knowledge as a disposition, which will put them in good stead for a sustainable and successful career as a teacher of D\&T. The Scottish Curriculum for Excellence, Welsh School Curriculum and the Northern Ireland Curriculum frame D\&T learning in different manners with similarities to each other at different points in the subject's evolution from a craft to a design-oriented curriculum.

\section{How is subject knowledge developed?}

It is important for beginning teachers to review subject knowledge development and identify priority areas for development relevant to the curriculum that they are teaching - just-in-time (JIT) learning (to borrow a manufacturing idiom) rather than blindly work through a subject knowledge audit ( $c f$ D\&TA 2017) or curriculum document without reference to what and when they will be teaching. The role of an experienced subject-specialist mentor is essential, as part of a regular dialogue around planning, teaching and evaluating, and the impact that it has on learning and progress. Appropriate areas for a mentor and beginning teacher to development will include:

- identifying gaps in subject content knowledge that is new (i.e. material that has not been previously studied); 
- refreshing existing subject content knowledge (i.e. material that has not studied for some time);

- developing and strengthening subject content knowledge that is going to be taught in the next term;

- breaking down existing subject content knowledge into its component parts in order to introduce it to learners for the first time (i.e. addressing areas of strength, which may be at a high level, come naturally or be the result of years of practice)

The last bullet, above, is possibly the most important and may be what separates an effective mentor from an effective teacher - i.e. an effective mentor enables the beginning teacher to recognises tacit knowledge, whereas an effective teacher my not necessarily be able to articulate what they are doing and why it works. Mentors and beginning teachers can address subject knowledge issues by:

- challenging preconceptions and assumptions about what pupils know and understand, and what is appropriate to their age and prior learning;

- reflecting on personal motivation and passion for the subject, which may be transferred as an unconscious assumption that all learners feel the same way;

- identifying and exploring common misconceptions and complex principles, concepts and processes;

Figure 6.3 uses the metaphor of a pyramid for subject knowledge, with a broad foundation of knowledge across a range of disciplines at a relatively low level. As the beginning D\&T teacher progressed through school, university, training and employment, a range of specific and narrower knowledge develops at a high level. Because of this specialisation, 'unused' knowledge is forgotten or ceases to be developed. For example, the D\&T teacher with a textiles background may have studied the discipline in primary (age 5-11) or lower secondary (age 11-14) and chosen it as an option for external examination at age 16. However, they may have taken an art based route post 16 and fashion design at university. Therefore, s/he may enter the professional 
with some D\&T knowledge at a high level, with significant gaps in technical knowledge to teach external examination syllabi. There is also the expectation that they teach across the range of D\&T disciplines in the secondary school curriculum, and the aforementioned need to break down complex knowledge.

\section{<COMP: Place Figure 6.3 Here>}

Issues with teaching may appear to be due to limited subject knowledge, but in reality be more to do with planning appropriate sequences of learning, focused on clear learning outcomes and supported by appropriate teaching and learning methods (i.e. the ability to successfully articulate knowledge with an understanding of learning). For example, experienced D\&T teachers may approach steps and procedures for processes differently in the classroom to how they would be in industry. This can be confusing for the beginning teacher, who may initially assume that the more experienced teacher is wrong or has weak/outdated knowledge; whereas the teacher may be making pragmatic and professional decisions to optimise learning in response to pedagogical/didactic and contextual factors. These factors may include:

- the age and prior experience of the learners;

- access to limited available resources in a class of 20 or more learners;

- managing risk, taking into account hazards and appropriate control measures;

- teaching wider principles beyond the specific activity, or using analogies develop conceptual understanding;

Subject knowledge is complex and beginning teachers develop it in five key ways:

1. build on prior knowledge, developed through education and experience;

2. formal training before, during and after ITE (e.g. health and safety);

3. mentoring during ITE and early career development, with experienced D\&T teachers;

4. self-directed subject knowledge development to expand and deepen knowledge and skill, through reading and doing (i.e. designing and/or making); 
5. learning through teaching - approaching planning, implementing and evaluating as practitioner enquiry;

\section{Summary}

This chapter has explored to help new D\&T teachers to analyse and develop knowledge and understanding in design and technology noting the following:

- $\quad$ subject knowledge is essential, but limited without the ability to successfully articulate it with an understanding of how children learn

- teacher knowledge includes knowledge of how schools structure the curriculum and how to children learn, alongside subject knowledge

- D\&T subject knowledge is complex and changing, and subject knowledge development for beginning teachers should focus on knowledge for teaching, prioritising short-, medium- and long-term needs

- potential pitfall for mentors to be aware of are gaps in knowledge, which can include areas either not studied recently (or at all) prior to teaching; and areas of seemingly strong subject knowledge where the 'building blocks' of complex knowledge may have been forgotten, leading to assumptions about what children will know or what motivates them

Figure 6.1 Teachers' professional knowledge (Banks, Leach and Moon 2005)

Figure 6.2 The interaction of hand and mind (Kimbell et al. 1991)

Figure 6.3 D\&T subject knowledge 


\section{Further Reading}

Design and Technology Educational Research Hub - http://www.dater.org.uk

International Journal of Technology and Design Education -

https://link.springer.com/journal/10798

\section{References}

Banks, F., Leach, J. and Moon, R. (2005). 'Extract from new understandings of teachers' pedagogic knowledge', The Curriculum Journal, 16(3), pp. 331-340.

Banks, F. and Owen-Jackson, G. (2007). 'The role of making in design \& technology', in Barlex, D. (ed.) Design and Technology for the Next Generation. Whitchurch: Cliffe and Company (Advertising and Marketing) Ltd. pp. 186-197.

Barlex, D. (2003). 'Considering the impact of design and technology on society - the experience of the Young Foresight project', The Place of Design \& Technology in the Curriculum, PATT13 Conference Proceedings. University of Glasgow. pp. 140-144

Barlex, D. (2006). 'The centrality of designing - an emerging realisation from three curriculum projects', in M. J. de Vries and I. Mottier (eds.). International Handbook of Technology Education. Rotterdam: Sense Publishers. pp. 253-259

Barlex, D. and Trebell, D. (2008). 'Design-without-make: Challenging the conventional approach to teaching and learning in a design and technology classroom', The International Journal of Technology and Design Education, 18(2), pp. 119-138.

Bell, D., Hughes, C. and Owen-Jackson, G. (2013). 'The (continuing) gender debate', in G. Owen-Jackson (ed.) Debates in Design and Technology Education. London: Routledge. pp. 153-165.

Bell, D., Morrison-Love, D., Wooff, D. and McLain, M. (2017). 'Analysing design and technology as an educational construct: An investigation into its curriculum position and pedagogical identity', The Curriculum Journal, 28(4), pp. 539-558.

Bernstein, B. (1990). The Structuring of Pedagogic Discourse: Class Codes and Control (Vol. IV). London: Routledge.

Black, P. and Harrison, G. (1985). In Place of Confusion: Technology and Science in the School Curriculum. London: Nuffield Chelsea Curriculum Trust. 
de Vries, M. (2012). 'Philosophy of technology', in Williams, P. J. (ed.) Technology Education for Teachers. Rotterdam: Sense Publishers. pp. 15-34.

de Vries, M. J. (2005). Teaching about Technology: An Introduction to the Philosophy of Technology for Non-philosophers. Netherlands: Springer.

DES/WO (1988). National Curriculum Design and Technology Working Group: Interim Report. London: Department for Education and Science/Welsh Office.

DES/WO (1989). Design and Technology for Ages 5 to 16: Proposal for the Secretary of State for Education and Science and for the Secretary of State for Wales. London: Department for Education and Science/Welsh Office.

Design and Technology Assocation (2017). Career Profile for Teachers of Design and Technology: Subject Competencies. Wellesbourne: D\&T Association. Available at: www.data.org.uk/resource-shop (Accessed: 28 July 2018).

DfE (2010). The Importance of Teaching: The Schools White Paper 2010. London: Department for Education. Available at: www.education.gov.uk/publications (Accessed: 28 July 2018). DfE (2011). The Framework for the National Curriculum. A Report by the Expert Panel for the National Curriculum Review. London: Department for Education. Available at: www.education.gov.uk/publications (Accessed: 28 July 2018).

DfE (2013a). National Curriculum in England: Design and Technology Programmes of Study. London: Department for Education. Available at: www.gov.uk/government/publications (Accessed: 28 July 2018).

DfE (2013b). Teachers' Standards: Guidance for School Leaders, School Staff and Governing Bodies. London: Department for Education. Available at: www.education.gov.uk/publications (Accessed: 28 July 2018).

DfE (2015a). Design and Technology GCSE Subject Content. London: Department for Education. Available at: www.gov.uk/government/publications (Accessed: 28 July 2018). DfE (2015b). Food Preparation and Nutrition GCSE Subject Content. Available at: www.gov.uk/government/publications (Accessed: 28 July 2018).

Ericsson, A. and Pool, R. (2016). Peak: Secrets from the New Science of Expertise. New York: Houghton Mifflin Harcourt.

Gettier, E. L. (1963). Is justified true belief knowledge? Analysis, 23(6), 121-123. 
Hattie, J. (2009). Visible Learning: A Synthesis of Over 800 Meta-Analyses Relating to Achievement. Abingdon, Oxon: Routledge.

Kimbell, R. and Perry, D. (2001). Design and Technology in a Knowledge Economy. London: Engineering Council.

Kimbell, R., Stables, K. and Green, R. (1996). Understanding Practice in Design and Technology. Buckingham: Open University Press.

Kimbell, R., Stables, K., Wheeler, T., Wosniak, A. and Kelly, V (1991). The Assessment of Performance and Design and Technology. London: Schools Examination and Assessment Council.

McCormick, R. (1997). 'Conceptual and procedural knowledge', International Journal of Technology and Design Education, 7(1-2), pp. 141-159.

McLain, M. (2012). 'An (auto) ethnographic narrative of the teaching of designing within design and technology in the English curriculum', Procedia Social and Behavioral Sciences, 45, pp. $318-330$.

McLain, M. (2017). 'Emerging perspectives on the demonstration as a signature pedagogy in design and technology', International Journal of Technology and Design Education, 28(4), pp. 985-1000.

McLain, M., Bell, D., Wooff, D. and Morrison-Love, D. (2018). 'Cultural and historical roots for design and technology education: Why technology makes us human', Research and Practice in Technology Education: Perspectives on Human Capacity and Development PATT Conference 2018. Ireland: Athlone Institute of Technology.

McLellan, R. and Nicholl, B. (2011). "'If I was going to design a chair, the last thing I would look at is a chair": Product analysis and the causes of fixation in students' design work 11-16 years', International Journal of Technology and Design Education, 22(1), pp. 71-92.

Mitcham, C. (1994). Thinking Through Technology: A Path between Engineering and Philosophy. Chicago, IL: The University of Chicago Press.

Morrison-Love, D. (2017). 'Towards a transformative epistemology of technology education', Journal of Philosophy of Education, 51(1), pp. 23-37.

Paetcher, C. (1995). 'Subcultural retreat: Negotiating the design and technology curriculum', British Educational Research Journal, 21(1), pp. 75-87. 
Qualifications and Curriculum Authority / Welsh Assembly / Council for the Curriculum, Examinations and Assessment (2007). GCSE Subject Criteria for Design and Technology. Available at: http://dera.ioe.ac.uk/7162/8/qca-07-3447_gcsecriteriadt.pdf (Accessed: 21 November 2018).

Ryle, G. (1949). The Concept of Mind. London: Penguin Books Ltd.

Scharff, R. C. and Dusek, V. (eds.) (2003). Philosophy of Technology: The Technological Condition, An Anthology. Oxford: Blackwell Publishing.

Shulman, L. S. (1986). 'Those who understand: Knowledge growth in teaching', Educational Research Review, 57(1), pp. 4-14.

Vygotsky, L. S. (1978). Mind in Society. Cambridge, MA: Harvard University Press. 